\title{
Studies on Mitochondrial Structure and Function in Physarum polycephalum. VII. Association between Mitochondrial Nuclear DNA and the Outer Limiting Membrane Complex
}

\author{
Tsuneyoshi Kuroiwa and Shigeyuki Kawano \\ Department of Cell Biology, National Institute for Basic Biology, Myodaiji, \\ Okazaki 444, Japan
}

\begin{abstract}
The spatial relationship between the mitochondrial nucleus (mt-nucleus) containing a large amount of DNA (mtDNA) and the mitochondrial limiting membrane in Physarum polycephalum was investigated. After labeling the mtDNA with $\left[{ }^{3} \mathrm{H}\right]$-thymidine, significant labels appeared over the space of the mitochondrial matrix as well as the mt-nucleus; this suggests that an appreciable amount of the mtDNA exists in the matrix. When the cristae and inner limiting membrane are removed selectively by Triton $\mathrm{X}$ 100 lysis, DNA-like fibers appear to extend from the mt-nucleus to the matrix space. One end of these fibers is attached to a knob-like structure that adheres to the outer limiting membrane of the mitochondrion. A portion of the mtDNA in the isolated mt-nucleus also extends from the mt-nucleus and is associated with mitochondrial membrane-like patches through the knob-like coupling. These results suggest that the mtDNA extends from the mt-nucleus throughout the mitochondrial matrix and that it is associated with the mitochondrial limiting membrane complex in the mitochondrion in situ.
\end{abstract}

The Physarum mitochondrion contains about 10 times more DNA than does other mitochondrion sources (5). The bulk of this DNA is localized mainly in an electron dense region, "the mitochondrial nucleus", situated in the central portion of the mitochondrion (16). However, $\left[{ }^{3} \mathrm{H}\right]$-thymidine autoradiography shows that small amounts of silver grains also appear over the non-nuclear region of the mitochondrial matrix (20, see RESULTS). Whole mount preparations have shown that a portion of the mtDNA in the mt-nucleus extends from the mt-nucleus and is associated with parts of the cristae and the mitochondrial membrane $(8,14)$. Therefore, an appreciable amount of mtDNA may exist within the non-nuclear part of the mitochondrial matrix in situ. However, the large amounts of cristae and matrix substances make direct observation of this DNA difficult. Recently, we reported that the mitochondrial cristae and the inner limiting membrane can be selectively removed from the mitochondria with Triton X-100 or Nonidet P-40, and that the mt-nucleus and outer limiting membrane remain intact (11-15).

The present paper documents the existence of mtDNA in the matrix extending from the mt-nucleus, that is bound to a mitochondrial outer limiting membrane complex. 


\section{MATERIALS AND METHODS}

Culture of plasmodia. Mitotically synchronized plasmodia of Physarum polycephalum and microplasmodia were prepared by the methods reviewed by Guttes and Guttes (2).

Electron microscopic autoradiography. Small explants of the plasmodium taken $5 \mathrm{~h}$ after the second post fusion mitosis (MII) were incubated in fresh medium containing $200 \mu \mathrm{Ci} / \mathrm{ml}$ $\left[{ }^{3} \mathrm{H}\right]$-thymidine (The Radiochemical Centre, Amersham, England, $25 \mathrm{Ci} / \mathrm{mmol}$ ) for $3 \mathrm{~h}$, then placed in fresh medium containing an excess of nonlabeled thymidine (100 times the concentration of the labeled thymidine) for $4 \mathrm{~h}$. These explants were fixed for $2 \mathrm{~h}$ in ice-cold $6 \%$ glutaraldehyde buffered with phosphate at $\mathrm{pH} 6.8$, then washed in ice-cold $5 \%$ trichloroacetic acid (TCA) for $5 \mathrm{~min}$. The samples were post-fixed in $1 \% \mathrm{OsO}_{4}$ for $12 \mathrm{~h}$, then dehydrated and embedded in Epon 812 according to the method previously described (18). Ultrathin sections were cut in a Sorval "Porter-Blum" ultramicrotome equipped with a glass knife. The sections were mounted on a grid coated with a Formval membrane.

Autoradiographic preparations for electron microscopy were prepared by procedures described previously (4). The exposure time was 2 months.

To determine whether the silver grains came from the $\left[{ }^{3} \mathrm{H}\right]$-thymidine incorporated into the DNA or were from compounds other than DNA, the cells were treated with enzymes, TCA or perchloric acid (PCA) before post-fixation in a solution of $1 \% \mathrm{OsO}_{4}$ fluid. Enzymatic digestions with $0.01 \%$ deoxyribonuclease (DNase) and $0.01 \%$ ribonuclease (RNase) were performed according to the procedure described previously $(8,6)$. Before use, DNase activity was extinguished by heating the RNase solution at $90^{\circ} \mathrm{C}$ for $10 \mathrm{~min}$. Acid soluble nucleotides were extracted from the cell samples with $2 \% \mathrm{PCA}$ at $0^{\circ} \mathrm{C}$ for $20 \mathrm{~min}$ (22). Extractions of RNA and the total nucleic acids were carried out with $10 \% \mathrm{PCA}$, at $23^{\circ} \mathrm{C}$ for $2.5 \mathrm{~h}$ and at $90^{\circ} \mathrm{C}$ for $30 \mathrm{~min}(3)$, respectively.

Grain counts were measured by procedures employed previously (7). Nuclei or mitochondria could be identified as labeled regions, when the number of grains exceeded four per unit area $\left(\mu \mathrm{m}^{2}\right)$, the level of the background after exposure for 2 months. The background was scored by counting the silver grains spread over non-tissue areas adjacent to each section scored.

Isolation of mitochondria. Two days after inoculation microplasmodia were washed twice with cold distilled water and resuspended in an equal volume of a cold solution containing $0.25 \mathrm{M}$ sucrose and $0.01 \mathrm{M}$ Tris- $\mathrm{HCl}$ buffer (pH 7.4). The suspension was homogenized in a teflon-glass homogenizer $(25 \mathrm{ml})$ with 6 strokes at $160 \mathrm{rev} / \mathrm{min}$. The homogenates were diluted 10 -fold by gently pipetting sucrose buffer solution into them, then they were centrifuged at $4^{\circ} \mathrm{C}$ for $3 \mathrm{~min}$ at $470 \times \mathrm{g}$ to remove slime. The resulting supernatant was filtered by gravity through two layers of nylon mesh with $31 \mu \mathrm{m}$ pores (NBC Ind., Japan) to remove large slime fragments and undisrupted microplasmodia. The filtrate was centrifuged for 5 $\mathrm{min}$ at $800 \times \mathrm{g}$ to remove the nuclei. Finally the mitochondria in the filtrate were sedimented as a pellet by centrifugation for $10 \mathrm{~min}$ at $4,000 \times \mathrm{g}$. Ultrathin sectioning of mitochondria in situ and of isolated mitochondria was performed as described previously $(6,12)$.

Detergent treatment. The mitochondrial pellet was resuspended in an 8 -fold volume of sucrose buffer solution to show the sharp distinction between the outer and inner limiting

Fig. 1. Electron microscopic autoradiographs of sections showing the cellular nucleus (NLO) and mitochondria containing mt-nuclei (MN) in Physarum plasmodium fixed $4 \mathrm{~h}$ after the end of a $3 \mathrm{~h}$ $\left[{ }^{3} \mathrm{H}\right]$-thymidine treatment. The majority of silver grains spread over the mitochondria are distributed over or near the mt-nuclei, but an appreciable number are spread over the mitochondrial matrix space and near the peripheral limiting membrane (arrows). (a) $\times 32,900$, (b) $\times 54,000$, (c) $\times 50,000$ 


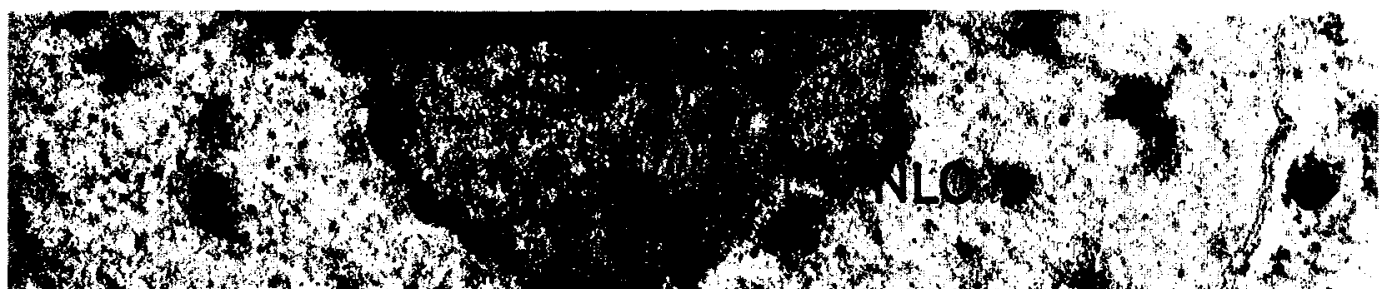

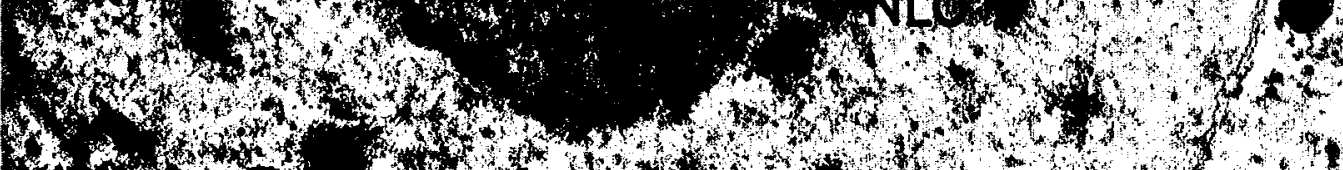

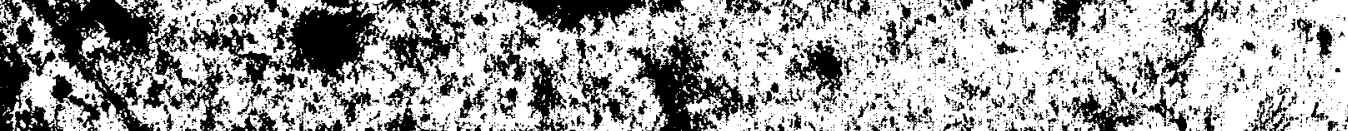

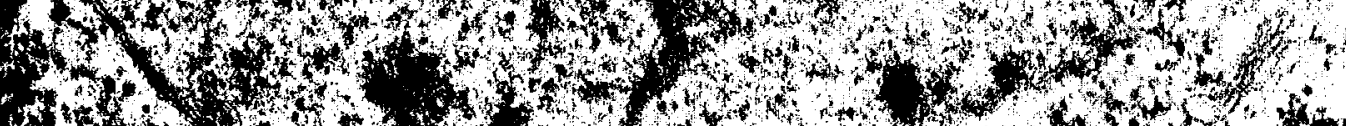

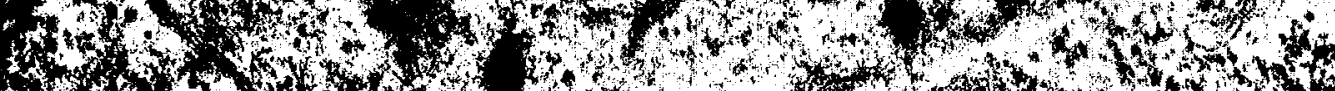

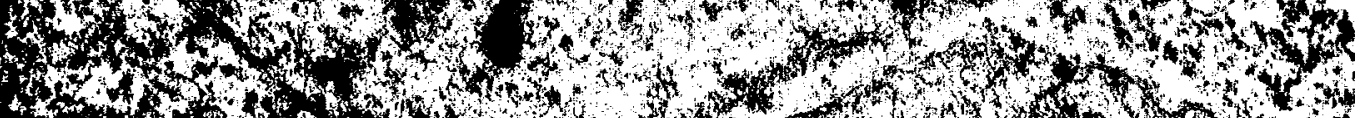

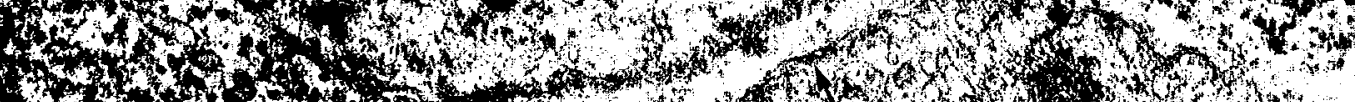

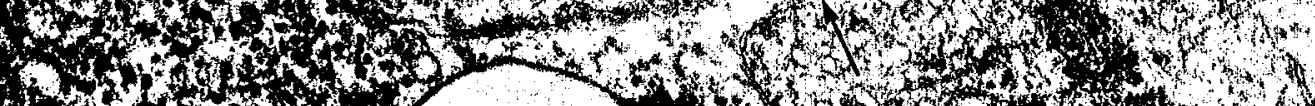

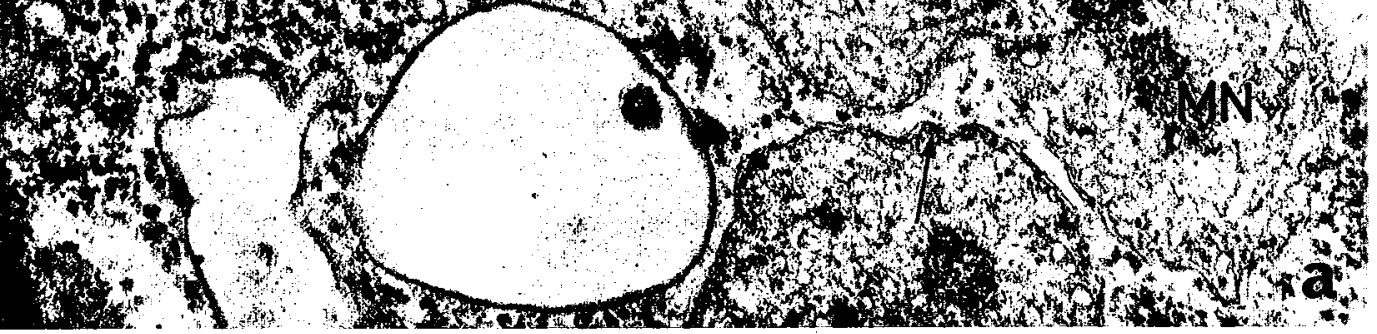

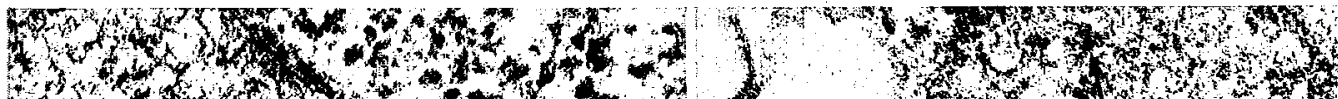

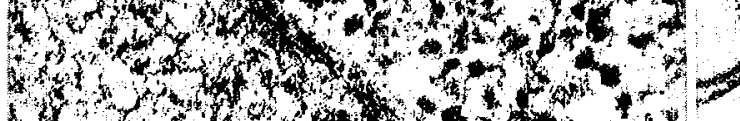
13.

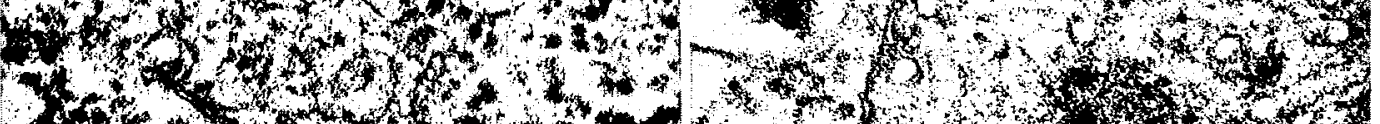

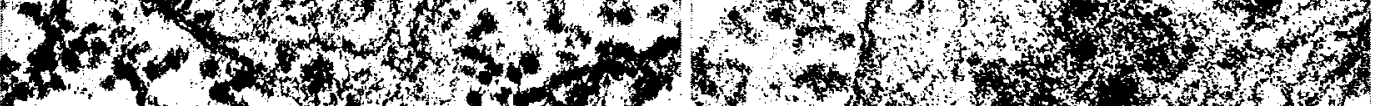

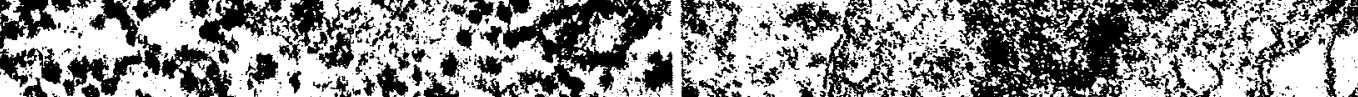

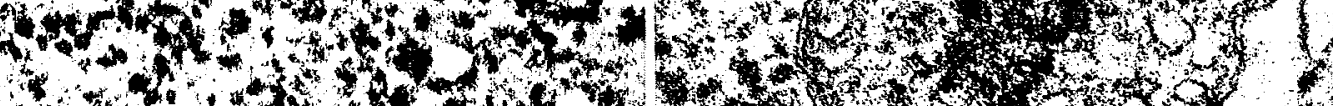

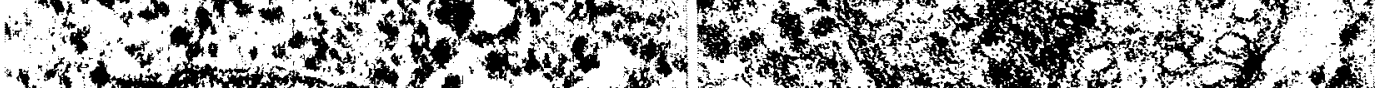

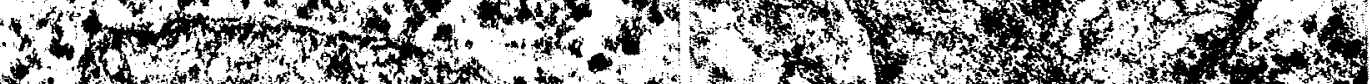

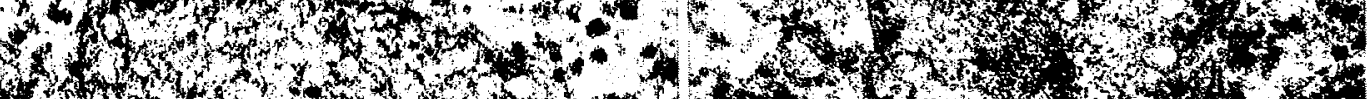

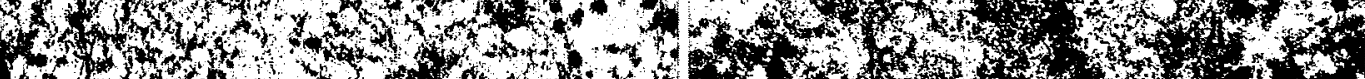

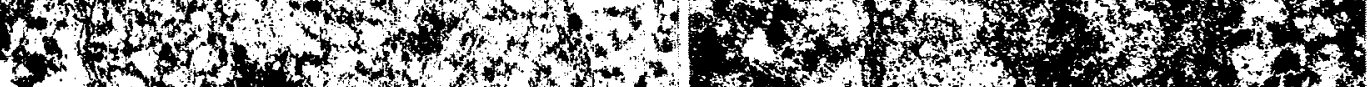

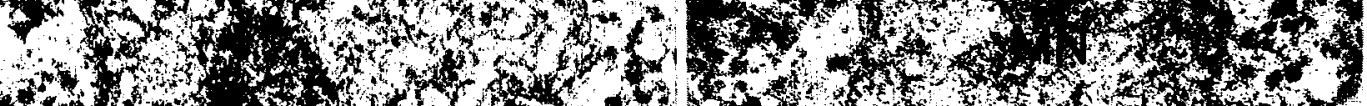

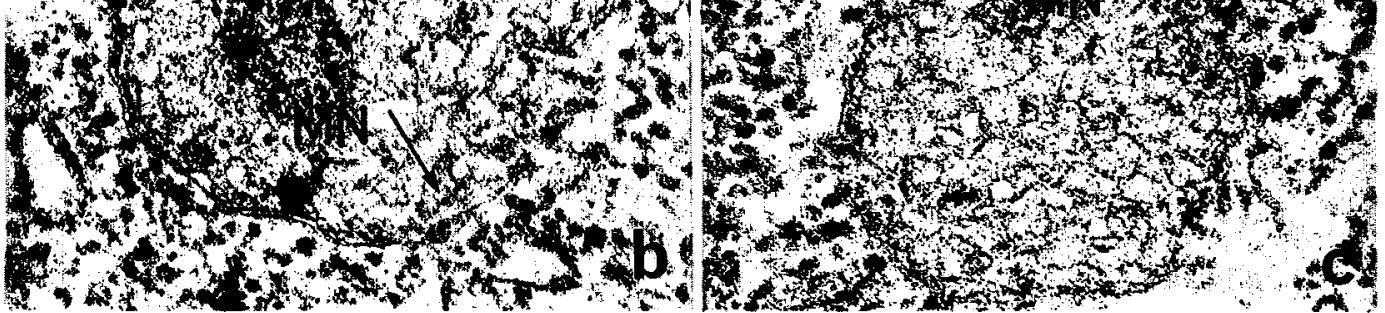


membranes of the mitochondrion. A one tenth volume of a $3 \%(w / v)$ aqueous solution of deoxycholate was added to the suspension and after several gentle pipettings, the mixture was incubated at $4^{\circ} \mathrm{C}$ for $10 \mathrm{~min}$. The resulting lysate was centrifuged at $5,500 \times \mathrm{g}$ for $5 \mathrm{~min}$. The electron microscopic specimens for the pellet obtained were prepared as described previously $(6,12)$.

To remove the cristae and the inner limiting membrane from isolated mitochondria, the mitochondrial pellet was resuspended in a 10 -fold volume of the sucrose buffer solution. Then a one tenth volume of a $10 \%$ aqueous solution of Triton X-100 was added to the suspension and after several gentle pipettings, the mixture was incubated for $5 \mathrm{~min}$ at $4^{\circ} \mathrm{C}$. The resulting lysate was centrifuged at $5,500 \times \mathrm{g}$ for $5 \mathrm{~min}$. Ultrathin sections of mitochondria treated with Triton X-100 were prepared as described previously (6).

To prepare whole mount mitochondria, the lysate was applied directly to a grid coated with a carbon membrane. Then the sample was air-dried and stored at room temperature until analysis. Samples were stained in $2 \%$ uranyl acetate for $15 \mathrm{~min}$ at room temperature, then dehydrated in a graded series of ethanol and amyl acetate, and air-dried. These samples were shadowed with platinum-palladium alloy in vacuo at an angle of $8^{\circ}$, then examined with a Hitachi-11E electron microscope $(80 \mathrm{kV})$.

Isolation of mitochondrial nuclei. To isolate the mt-nuclei, the mitochondrial pellet was resuspended in an 8-fold volume of the sucrose buffer solution. A one tenth volume of $1 \%$ aqueous solution of Nonidet P-40 was added to the suspension, then after gentle pipetting the whole was incubated for $5 \mathrm{~min}$ at $4^{\circ} \mathrm{C}$. The clear lysate was centrifuged at $5,500 \times \mathrm{g}$ for 5 min to remove heavy debris, such as nonsoluble mitochondria. Seven milliliters of the supernatant was layered onto $5 \mathrm{ml}$ of $1 \mathrm{M}$ buffered sucrose in a $13 \mathrm{ml}$ centrifuge tube; then the sample was centrifuged in a Hitachi RPS $40 \mathrm{~T}$ rotor at $60,000 \times \mathrm{g}$ for $30 \mathrm{~min}$. The mtnuclei were collected as a pellet.

\section{RESULTS}

Distribution of silver grains over a mitochondrion. Electron microscopic autoradiography has been used to study the distribution of mtDNA in the mitochondrion. Fig. 1a-c shows the distribution patterns of the silver grains on a plasmodium in $\mathrm{G}_{2}$-phase. Some of mitochondria were elongated and contained a rodlike mt-nucleus (Fig. 1a, c). The mitochondria shown at the left of Fig. 1a and in Fig. 1b appeared to be cross sections of the elongated mitochondria. Although much label was present over the nucleolus and nucleoplasm, the majority of the grains were distributed over the mitochondria (Fig. 1a). In addition, in a mitochondrion the label was predominantly localized over and near the electron dense mt-nuclei (Fig. 1a-c). Some labels, however, were distributed over the matrix space and near the region of the limiting membrane (arrows in Fig. 1a-c). Grain counts (Table 1) were made to measure quantitatively the relative amounts of label found over the mitochondrial matrix. The matrix of the mitochondria contains about 10 times as much label as the back-

Fig. 2. Electron micrographs of sections showing the Physarum mitochondrion in situ (a) and isolated mitochondria before (b) and after (c) deoxycholate treatment. Isolated mitochondria are similar in configuration to the mitochondria in situ, except that no electron dense convex lenslike particles are spread over the inner limiting membrane (short arrows in b); they are seen over the outer limiting membrane (long arrows in b). The distinction between the outer limiting membrane with the electron dense convex lens like particles (arrow in c) and inner limiting membrane is clear, but the mt-nucleus cannot been seen. (a) $\times 36,000$, (b) $\times 38,000$, (c) $\times 58,000$ 


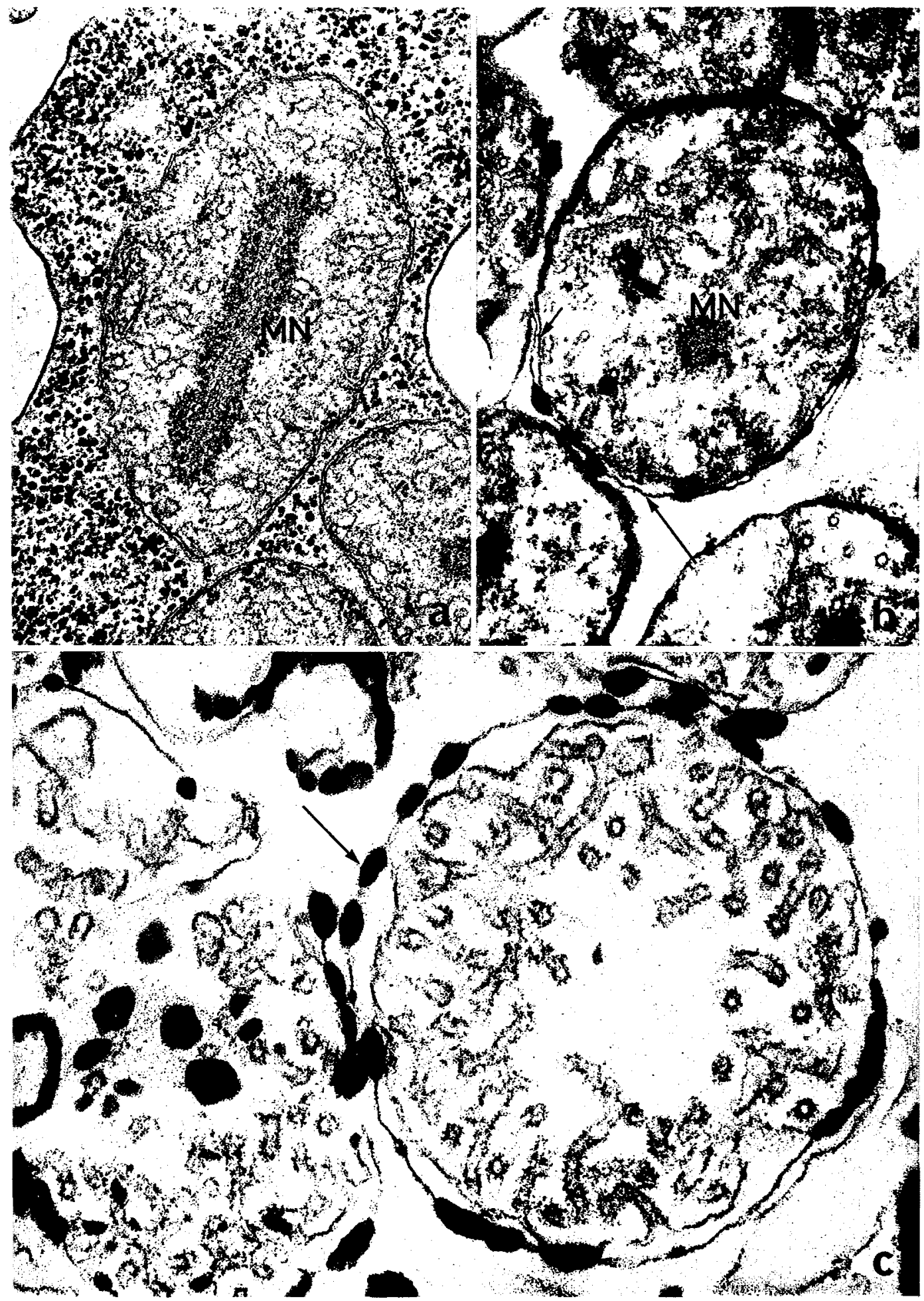


TABLE 1. Distribution of GRAins IN THE PLASModium DURING $\mathrm{G}_{2}$ FIXED AT $4 \mathrm{~h}$ AFTER $\left[{ }^{3} \mathrm{H}\right]$-THYMIDINE TREATMENT FOR $3 \mathrm{~h}$

\begin{tabular}{cc}
\hline Area & No. of silver grains/Unit area $\left(\mu \mathrm{m}^{2}\right)$ \\
\hline Background & $0.27 \pm 0.24$ \\
Cytoplasm & $0.50 \pm 0.20$ \\
Nuclei $\left\{\begin{array}{l}\text { Nucleoplasm } \\
\text { Nucleoli }\end{array}\right.$ & $55.70 \pm 1.20$ \\
Mitochondria $\begin{cases}\text { Nuclei } \\
\text { Matrix }\end{cases}$ & $35.10 \pm 16.40$ \\
\end{tabular}

ground and one tenth as much label as the mt-nucleus.

To test whether the labels result from the incorporation of $\left[{ }^{3} \mathrm{H}\right]$-thymidine into DNA or into compounds other than DNA, small blocks of glutaraldehyde-fixed plasmodium were treated with $5 \%$ TCA, followed by enzymatic digestions then by TCA or PCA treatment. The radioactivity of the mitochondria after treatment with TCA, RNase and PCA $\left(2 \%, 0{ }^{\circ} \mathrm{C}, 30 \mathrm{~min}\right.$ or $\left.10 \%, 25^{\circ} \mathrm{C}, 2.5 \mathrm{~h}\right)$ (Table 2$)$ did not differ significantly from that of the control buffer, whereas after the DNase or PCA $\left(10 \%, 90^{\circ} \mathrm{C}, 30 \mathrm{~min}\right)$ treatment it was lowered. These results indicate that nearly all the labels over the mitochondria represent labeled DNA; and that is evidence for the existence of a small amount of mtDNA in the matrix.

Visualization of $m t D N A$ in the matrix by Triton $X-100$ treatment. Electron microscopy cannot make clear the mtDNA filaments in the matrix because of the presence of many tubular cristae and a fairly electron dense matrix within the mitochondria. Thus, to study the distribution or behavior of the mtDNA fibers within the matrix, we must selectively remove cristae by mild treatment. The Triton X-100 method was used to remove both the mitochondrial cristae and the inner limiting membrane from isolated mitochondria $(12,14)$.

TABLE 2. DISTRIBUTION OF GRAINS OVER THE MITOCHONDRIAL NUCLEUS AND MATRIX IN THE PLASMODIUM DURING $\mathrm{G}_{2}$ FIXED AT $4 \mathrm{~h}$ AFTER $\left[{ }^{3} \mathrm{H}\right]$-THYMIDINE TREATMENT WITH AND WITHOUT TCA OR ENZYMATIC POST-TREATMENT

\begin{tabular}{lcc}
\multicolumn{1}{c}{ Treatment } & Mitochondrial Nucleus & Matrix \\
\hline Control $^{\mathrm{a}}$ & $28.3 \pm 11.2^{\mathrm{b}}$ & $3.0 \pm 1.0$ \\
TCA $\left(5 \%, 3^{\circ} \mathrm{C}, 30 \mathrm{~min}\right)$ & $25.4 \pm 9.6$ & $2.9 \pm 1.1$ \\
RNase $\left(0.01 \%, 37^{\circ} \mathrm{C}, 3 \mathrm{~h}\right)+\mathrm{TCA}\left(5 \%, 3^{\circ} \mathrm{C}\right.$, & $24.5 \pm 7.9$ & $3.1 \pm 0.8$ \\
30 min $)$ & & \\
DNase $\left(0.01 \%, 37^{\circ} \mathrm{C}, 3 \mathrm{~h}\right)+\mathrm{TCA}\left(5 \%, 3^{\circ} \mathrm{C}\right.$, & $1.9 \pm 0.7$ & $0.2 \pm 0.01$ \\
$30 \mathrm{~min})$
\end{tabular}

a Controls were incubated in acetate buffer $\mathrm{pH} 6.8$ at $37^{\circ} \mathrm{C}$ for $3 \mathrm{~h}$ without enzyme.

b Mean number of grains with S. D. per 10 mitochondria.

Fig. 3. Electron micrographs of sectioned (a-c) and shadowed (d) preparations showing mitochondria after Triton X-100 treatment. Cristae and the inner limiting membrane have been digested, but the outer limiting membrane with convex lenslike particles and the mt-nucleus (MN) consisting of fine fibers (short arrows in a, b) remain. Fine DNA fibers extending from the mt-nucleus are attached to the membrane throughout a knoblike structure (long arrows in $b, c)$. (a) $\times 63,000,(b)$ $\times 63,000$, (c) $\times 49,500$ 

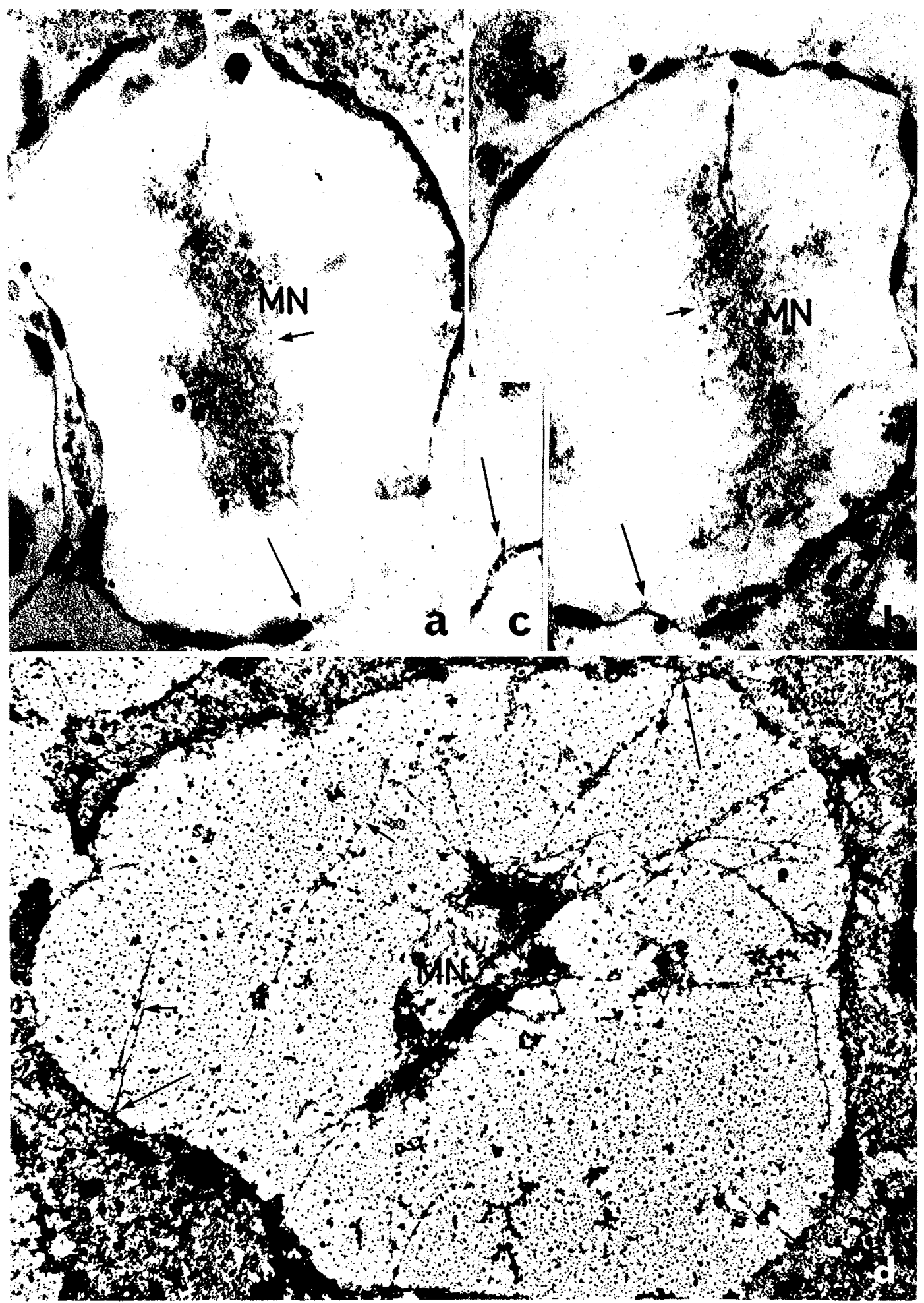
Figs. 2a-c and 3a-d show electron micrographs of intact mitochondria (Fig. 2a) and isolated mitochondria before (Fig. 2b) and after Triton X-100 treatment (Fig. $3 a-d)$. The isolated mitochondria closely resembled those found in situ (Fig. 2a); they maintained the shape and internal structure of intact mitochondria. Each contained an electron dense mt-nucleus (Fig. 2b) and both the outer and inner limiting membranes were observable as well as many tubular cristae (Fig. 2b). Electron dense convex lenslike structures $1,000-3,000 \AA$ in diameter and $500-1,500 \AA$ in width appeared on the outer limiting membrane (long arrows in Fig. 2b) but not on the inner limiting membrane (short arrows in Fig. 2b). The inner limiting membrane was clearly distinguished from the outer limiting membrane after $0.3 \%$ deoxycholate treatment (Fig. 2c). In addition, the inner limiting membrane had rough surface cristae. This may be the result of the attachement of numerous mitochondrial unit particles ( $90 \AA$ in diameter) to the surface of the tubular cristae. The electron dense mt-nucleus disappeared completely although some fine DNA fibers remained in the empty mt-nuclear region due to removal of the mt-nuclear proteins by deoxycholate extraction. After the Triton X-100 treatment, the cristae and internal matrix were digested completely but an electron dense mt-nucleus and a single limiting membrane with many electron dense convex lenslike particles remained (Fig. 3a, b) (12). The membrane observed was identified as the outer limiting membrane, because the convex lenslike particles were associated only with the outer limiting membrane of the isolated mitochondria, as described above (Fig. 2b, c) (14). In most cases the $\mathrm{mt}$-nuclei remained intact in the central region of the mitochondrion and consisted of

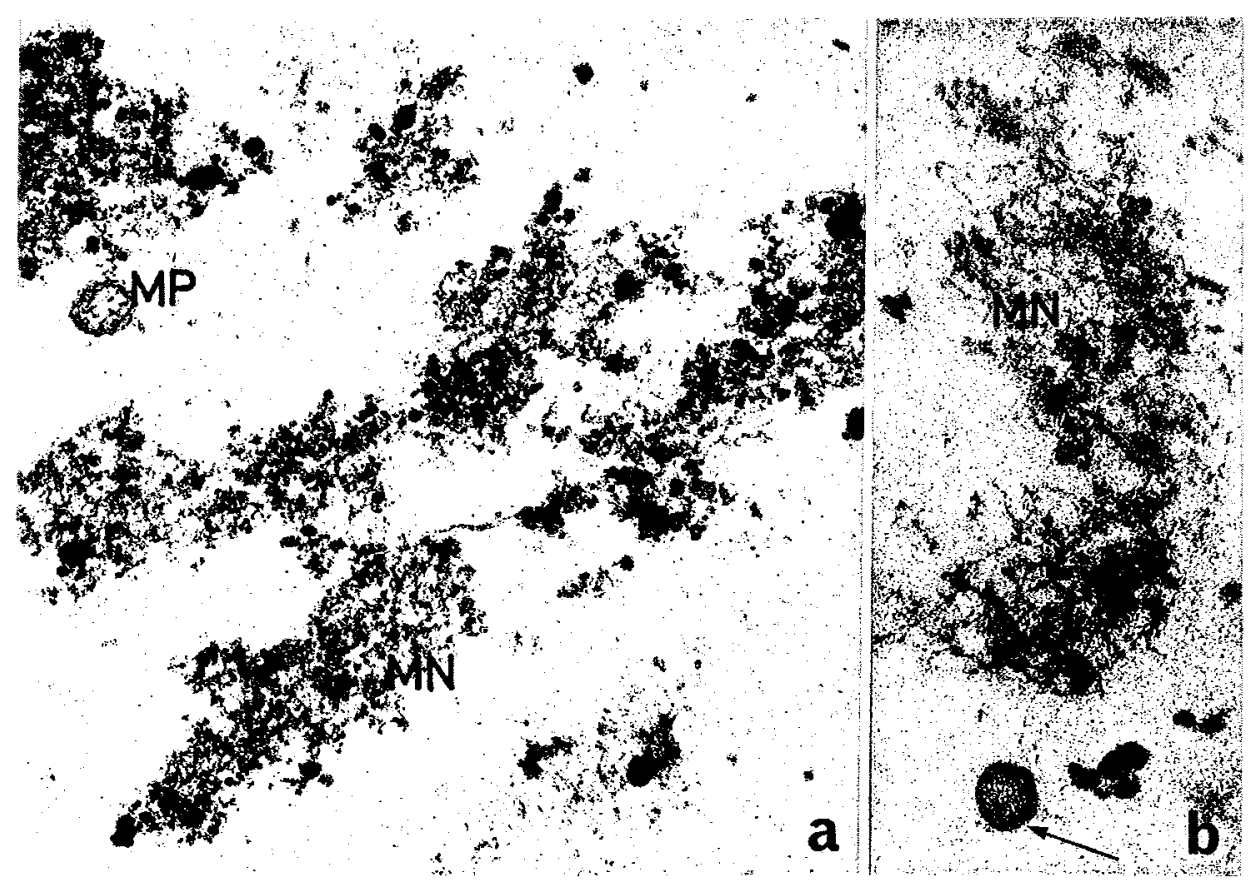

Fig. 4. Electron micrographs of sections of the isolated mt-nuclei (MN). The swollen mt-nuclei are attached to membrane-like patches (MP) $(a, b)$, one of which shows a single unit membrane structure (long arrow in b). (a) $\times 51,000$, (b) $\times 86,300$ 
both fine DNA fibers (short arrows in Fig. 3b) $(14,7)$ and fine granules. A few fine fibers $20-200 \AA$ in diameter were spread radially from the distal ends of the mt-nuclei and often were connected to the outer limiting membrane (long arrows in Fig. 3a-c). At a higher magnification, the attachment site of some mtDNA fibers to the outer limiting membrane appeared to be somewhat thicker than the mtDNA fibers (Fig. $3 c)$. This association between the mtDNA and the limiting membrane also was observed for the whole mounted mitochondrion after Triton X-100 treatment (Fig. $3 \mathrm{~d}$ ). Fine fibers radiated from both ends of the mt-nucleus and some of them were associated with the limiting membrane. Only a few fibers had diameters larger than average. This may due to the interwinding and/or clumping of fine fibers of 40-70 in diameter (short arrows shown in Fig. 3d). These fine filaments probably consist of DNA since they could be disrupted with DNase, but not with RNase (8). The sites at which the threads are connected with limiting membrane region were slightly thicker (long arrows in Fig. 3d) than the other parts. These results suggest that the label that appeared over the matrix came from the labeled mtDNA that connected the mt-nucleus with the mitochondrial limiting membrane.

Isolation of the mitochondrial nucleus with the limiting membrane by treatment with

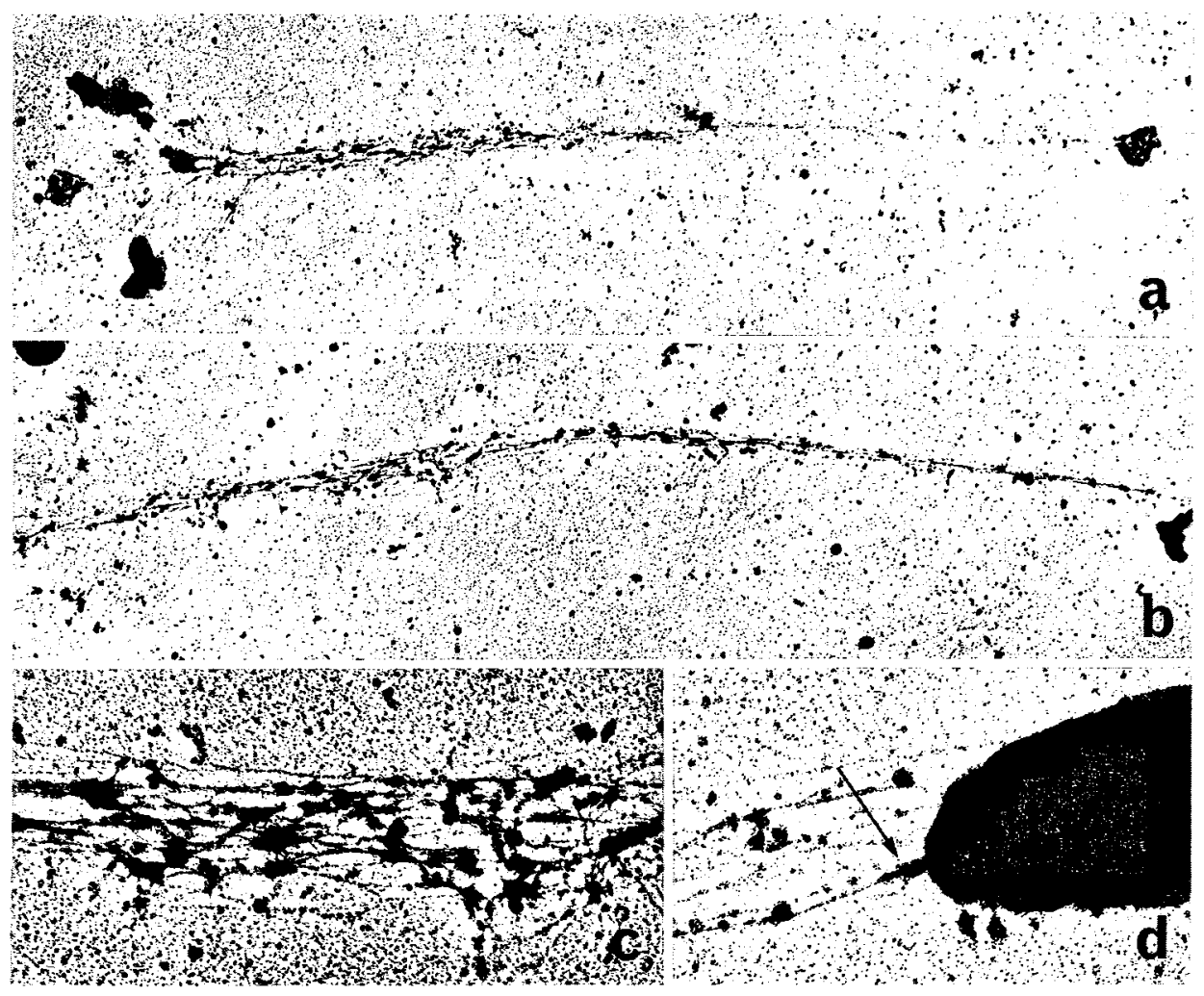

Fig. 5. Electron micrographs of surface-spread and shadowed mt-nuclei isolated by Nonidet P-40. DNA-like fibers are arranged parallel to the long axis of the mt-nuclei (a-c). Fig. $5 \mathrm{c}$ is a higher magnification micrograph of a portion of Fig. $5 \mathrm{~b}$. At the distal ends, the mt-nuclei are attached to membranelike patches $(a, b, d)$. The attachment sites between the mtDNA and the limiting membrane looks like a knob (arrow in d).

(a) $\times 10,100$, (b) $\times 9,600$, (c) $\times 44,800$, (d) $\times 64,000$ 
Nonidet P-40. Thin sections of the isolated mt-nucleus obtained by mild Nonidet P-40 treatment showed that some of the mt-nuclei were attached to a thin membranelike patch (Fig. 4a), a cross-section of which showed a unit membrane structure (arrow in Fig. 4b). The mt-nucleus of the whole-mounted mitochondria was swollen to $10-18 \mu \mathrm{m}$ in length and about $0.3 \mu \mathrm{m}$ in width. Both ends of the mt-nucleus were connected with one or more of the membrane-like patches (Fig. 5a, b); these probably are fragments of the outer limiting membrane since the inner limiting membrane had been dissolved completely by Nonidet P-40 treatment $(14,12)$. At a high magnification, many of the DNA-like fibers in the mt-nucleus were predominantly orientated parallel to the long axis of the mitochondrion (Fig. 5c). This suggests that the mtDNA molecules mainly are organized in a longitudinal direction. In several instances, although the parallel arrangement was retained, the fibers formed networks in some parts of the mt-nucleus. The DNA fibers extending from the mt-nucleus were connected to the membrane with a knob-like structure. The connective structure was about three times as thick as a DNA fiber (arrows in Fig. 5d), and it was completely disrupted by trypsin treatment (9).

These results suggest that some of the mtDNA is strongly connected with the outer limiting membrane by a knob-like structure composed of proteins that are digestible with trypsin.

\section{DISCUSSION}

The mitochondrion of Physarum polycephalum contains an electron dense, large rod-like mt-nucleus composed of a large amount of DNA, RNA and protein; it is situated in the center of the inner matrix. $\left[{ }^{3} \mathrm{H}\right]$-thymidine autoradiography of Physarum mitochondria in situ and Triton X-100 treatment of isolated mitochondria revealed that the bulk of the mtDNA is located in the electron dense mt-nucleus, but that an appreciable amount of mtDNA is distributed in the matrix space (Figs. 1, 2). This matrix DNA appears to be a DNA that joins the mt-nucleus with the mitochondrial limiting membrane (Figs. 3-5).

There are two possible ways that mtDNA may be connected to the mitochondrial limiting membrane: One is that mtDNA binds to the inner limiting membrane $(19,1)$

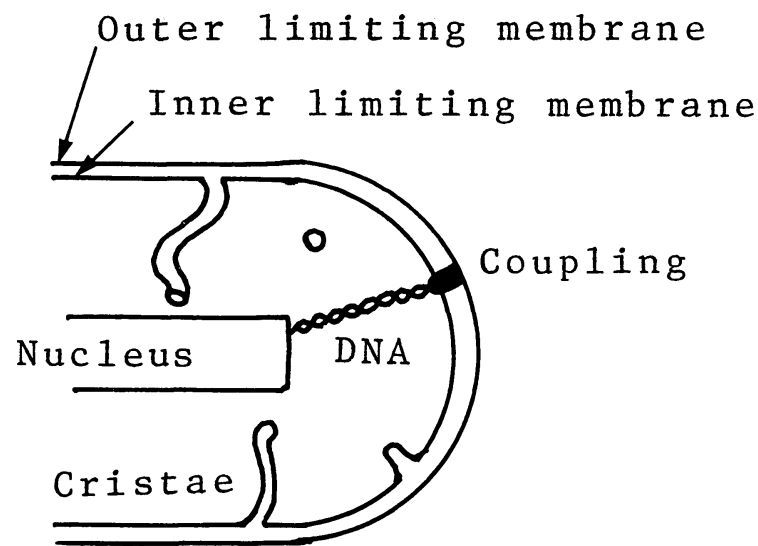

Fig. 6. A model for the attachment site between mtDNA and the limiting membrane. 
and the other is that it binds to the outer limiting membrane by penetrating through the inner limiting membrane (14). The results presented here have confirmed that while the outer limiting membrane and the mt-nucleus remain after Triton X-100 or Nonidet P-40 treatment, the cristae and inner limiting membrane are specifically removed (Fig. 3a, b, d). The binding site of the mtDNA that extends from the mtnucleus to the mitochondrial outer limiting membrane showed a knob-like structure that was predominantly composed of proteins. These observations led us to assume a structure in which a coupling protein exists that helps mtDNA to connect to the outer limiting membrane (Fig. 6). If the mitochondrion is not subjected to detergent treatment, parts of the inner limiting membrane around this coupling would remain unchanged and the resulting image would appear as if the mtDNA is associated with the inner limiting membrane.

Although the significance of the connection between mtDNA and the membrane system is not clear, analogy to bacterial chromosomes suggests several possibilities (21). It has been suggested that mtDNA synthesis and the segregation of mtDNA molecules during mitochondrial division depend upon membrane association. From observations of isolated mitochondria Nass (19) assumed that the association site of mtDNA with the membrane may represent the site of mtDNA replication. Recently, Albring et al. (1) used high resolution electron microscopy and polyacrylamide gel electrophoresis on mtDNA cleft with the endonucleases and suggested that HeLa cell mtDNA is attached in vivo to the inner mitochondrial membrane at or near the origin of replication. If the association site in Physarum polycephalum is related to the origin of mtDNA replication, then after a short pulse labeling with $\left[{ }^{3} \mathrm{H}\right]$-thymidine the label must appear over or near the membrane. However, analyses of Physarum mtDNA by high resolution electron microscopic autoradiography after a short pulse labeling with $\left[{ }^{3} \mathrm{H}\right]$-thymidine have shown that the label is not localized over the membrane but is spread over the peripheral and inner region of the mt-nucleus where mtDNA fibers are situated (10). Therefore, it is unlikely that in Physarum polycephal$u m$ the association between mtDNA and the limiting membrane plays an important role in mtDNA synthesis. On the other hand, we observed that the mtDNA extends from the distal ends of the rodlike mt-nucleus and that the distal ends of the isolated $\mathrm{mt}$-nucleus are attached to membranelike patches (Figs. 3-5). This elongated mtnucleus is found in mitochondria during the mitochondrial $G_{2}$ or mitochondrial $M$ phase (16). Thus, this association between mtDNA and the mitochondrial membrane may be related to segregation of the mtDNA molecules into daughter mitochondria. It has been estimated, however, that Physarum mitochondria contain many DNA molecules (about 40) (8). Although there have been many explanations for DNA membrane association, the most likely explanation is that mtDNA is released from the limiting membrane during isolation of the mitochondrion or the mt-nucleus. We reported that mitochondria of Physarum polycephalum divided semisynchronously during late $S$ (17). If we can succeed in isolating mitochondria at various stages during the mitochondrial division cycle, then the functional significance of the association probably could be elucidated.

Acknowledgements. We thank Dr. D. Callen (Department of Health, Education Welfare, National Institute of Environmental Health Sciences, Research Triangle Park, N.C. 27709) for his critical reading of the manuscript. This work was supported in part by Grants No. 148018 and No. 1311202 (T. Kuroiwa) from the Ministry of Education, Science and Culture, Japan. 


\section{REFERENCES}

1. Albring, M., J. Griffith and G. Attardi. Association of a protein structure of probable membrane derivation with HeLa cell mitochondrial DNA near its origin of replication. Proc. Natl. Acad. Sci. U.S.A. 74, 1348-1352, 1977

2. Guttes, E. and S. Guttes. in Methods in Cell Physiology. D.M. Prescott, editor. Academic Press, Inc., New York Vol. 1, 43-53, 1964

3. Hermann, R.G. Multiple amounts of DNA related to the size of chloroplasts. Planta. 90, 80-96, 1970

4. Kuroiwa, T. and N. Tanaka. Asynchronous dispersion of chromosomes from telophase to $\mathrm{G}_{1}$ period as revealed by electron microscopic autoradiography. Exptl. Cell Res. 65, 177-185, 1971

5. Kuroiwa, T., A. Hama, K. Horiba and A. Nukazawa. Isolation of nuclei and mitochondria of Physarum polycephalum. Proceedings of the 38th Annual Meeting of the Botanical Society of Japan, pp. 72, 1973

6. Kuroiwa, T. Studies on mitochondrial structure and function in Physarum polycephalum. I. Fine structure, cytochemistry, and $\left[{ }^{3} \mathrm{H}\right]$-uridine autoradiography of a central body in mitochondria. Exptl. Cell Res. 78, 351-359, 1973

7. KuroIWA, T. Fine structure of interphase nuclei. VI. Initiation and replication sites of DNA synthesis in the nuclei of Physarum polycephalum as revealed by electron microscopic autoradiography. Chromosoma. 44, 291-299, 1973

8. Kuroiwa, T. Studies on mitochondrial structure and function in Physarum polycephalum. III. Electron microscopy of a large amount of DNA released from a central body in mitochondria by trypsin digestion. J. Cell Biol. 63, 299-306, 1974

9. Kuroiwa, T. A large amount of DNA released from mitochondria by osmotic shock following trypsin treatment. J. Electron Microscopy 23, 117-119, 1974

10. Kuroiwa, T. Sites of DNA synthesis in the mitochondria of Physarum polycephalum as revealed by electron microscopic autoradiography. J. Electron Microscopy 23, 121-123, 1974

11. Kuroiwa, T. Mitochondrial nucleoid. The Cell 7, 14-34, 1975 (in Japanese)

12. Kuroiwa, T., S. Kawano and M. Hizume. A method of isolation of mitochondrial nucleoid of Physarum polycephalum and evidence for the presence of a basic protein. Exptl. Cell Res. 97, 435- 440, 1976

13. Kuroiwa, T. Replication and segregation of mitochondrial DNA. Proceedings of the 42th annual meeting of the genetic sociaty of Japan, p.52, 1976

14. KuroIWA, T. Isolation of mitochondrial nuclei and their fine structures. J. Electron Microscopy 25, 182, 1976

15. Kuroiwa, T. and S. Kawano. Mitochondrial nuclear DNA and the mitochondrial limiting membrane. Proceedings of the 42th annual meeting of the botanical society of Japan, pp 84, 1976

16. Kuroiwa, T., S. Kawano and M. Hizume. Studies on mitochondrial structure and function in Physarum polycephalum V. Behavior of mitochondrial nucleoids throughout the mitochondrial division cycle. J. Cell Biol. 72, 687-694, 1977

17. Kurorwa, T. Studies on mitochondrial structure and function in Physarum polycephalum. IV. Mitochondrial division cycle. Cytologia 43, 119-136, 1978

18. LufT, J.H. Improvements in epoxyresin embedding methods. J. Biophys. Biochem. Cytol. 9, 409-418, 1961

19. Nass, M.M.K., S. Mass and B.A. AfZelius. The general occurrence of mitochondrial DNA. Exptl. Cell Res. 37, 516-539, 1965

20. RYSER, U., S. FAKAN and R. BRAUN. Localization of ribosomal RNA genes by high resolution autoradiography. Exptl. Cell Res. 78, 89-97, 1973

21. Ryter, A. Association of the nucleus and the membrane of bacteria: a morphological study. Bacteriol. Rev. 32, 39-54, 1968

22. Woods, P.B. and J.H. TAYLOR. Studies of ribonucleic acid methabolism with tritium-labelled cytidine. Lab. Invest. 8, 309-328, 1959 